\title{
Relationship Between Insulin-mediated Glucose Disposal and Lipid Metabolism in Man
}

Stephen Lillioja, Clifton Bogardus, David M. Mott, Annette L. Kennedy, William C. Knowler, and Barbara V. Howard

Phoenix Clinical Research Section, and Southwestern Field Studies Section, National Institute of Arthritis,

Diabetes, Digestive, and Kidney Diseases, National Institutes of Health, Phoenix, Arizona 85016

\section{Abstract}

To assess the possible effects of lipid metabolism on insulinmediated glucose disposal, 18 nondiabetic Pima Indian women (age 18-35 yr) were studied using $1-{ }^{14} \mathrm{C}$-palmitate infusion to measure free fatty acid turnover rate followed by a euglycemic clamp (clamp) to measure in vivo insulin-mediated glucose disposal (M). Indirect calorimetry was performed in the basal state and during the clamp. This was used to assess glucose oxidation rate, lipid oxidation rate, and to calculate nonoxidative glucose disposal (storage). Basal and clamp lipid oxidation rate correlated with basal plasma free fatty acid concentration ( $r=0.81, P \leq 0.0001, r=0.67, P<0.003$, respectively). The fall in lipid oxidation was highly correlated with the increase in glucose oxidation during the insulin infusion $(r=0.96, P$ $\leq \mathbf{0 . 0 0 0 1}$ ). The clamp lipid oxidation rate negatively correlated with the glucose oxidation rate $(r=-0.85, P \leq 0.0001)$ and with the $M$ value $(r=-0.60, P<0.01)$ but was not correlated with the clamp glucose storage $(r=-0.2, P=0.4)$. On the other hand, glucose storage appeared to make a greater contribution to the difference in $M$ value between the upper and lower extremes of $M$ than did glucose oxidation, as evidenced by an increase in glucose storage of $0.59 \mathrm{mg} / \mathrm{kg}$ fat-free mass times minute per $1 \mathrm{mg} / \mathrm{kg}$ fat-free mass times minute increase in glucose disposal. The $M$ value was negatively correlated with obesity as measured by percent body fat $(r=-0.64, P$ $<0.004$ ), but neither basal free fatty acid concentration, basal free fatty acid turnover, basal lipid oxidation, nor clamp lipid oxidation correlated with percent body fat.

We conclude that an interaction of lipid and glucose metabolism in a glucose fatty acid cycle, as proposed by Randle et al. (1), may be operative in the regulation of glucose oxidation in man. The disposal of glucose however has two components. The storage component does not appear to be associated with lipid oxidation in the way that the oxidative component is and may be regulated by a different mechanism. Since the results show that the glucose storage component plays a significant role in distinguishing between those with low and high $M$ values, we suggest that the glucose fatty acid cycle can, at best, only partially explain impaired in vivo insulin-mediated glucose disposal. Furthermore, the data suggest that the impact of obesity on in vivo insulin resistance appears to be mediated by factors other than changes in lipid availability or metabolism.

Address reprint requests to Dr. Howard.

Received for publication 7 May 1984 and in revised form 28 November 1984

The Journal of Clinical Investigation, Inc.

Volume 75, April 1985, 1106-1115

\section{Introduction}

20 yr ago, Randle et al. (1) proposed a glucose fatty acid cycle, wherein an increased availability of fatty acids and ketone bodies for oxidation might be responsible for alterations of carbohydrate metabolism in muscle, in diabetes mellitus, starvation, and carbohydrate deprivation. Aspects of this proposed biochemical syndrome included impaired in vivo insulin action and impaired glucose tolerance. This concept was extended with the suggestion that one distinct role of insulin was to control glucose uptake via variations in the rate of fatty acid mobilization from adipose tissue $(2,3)$. Recently, the important role of ketones-intermediate metabolic products of free fatty acids (FFAs) ${ }^{1}$-in regulating key sites of the glucose oxidative pathway has been emphasized $(3,4)$ and the initial Randle hypothesis has been extended to a glucose fatty acid ketone body cycle (3).

The physiological basis for the proposal of Randle and coworkers has been the subject of a number of reviews and discussions (1-8). Fatty acids or ketones inhibit glucose oxidation and uptake in perfused rat heart, or diaphragm by regulating key enzymes, viz pyruvate dehydrogenase and phosphofructokinase. The accumulation of glucose-6-phosphate from the latter inhibition in turn inhibits hexokinase. The presence of an inhibition of carbohydrate metabolism by fatty acids or ketones in skeletal muscle has been more controversial, but recent views favor this interaction (4, 9-11). Inhibition of glucose oxidation by ketones has also been demonstrated in brain, kidney, and small intestine (4).

Consistent with these in vitro studies are the findings of a number of in vivo studies. Infusions of nicotinic acid or related compounds are accompanied by a fall in plasma FFAs and an increase in whole body glucose oxidation as measured by labeled $\mathrm{CO}_{2}$ production or by indirect calorimetry (12-14). Elevations of plasma FFAs with lipid/heparin infusions decrease glucose oxidation assessed by the same techniques. (14-18). Changes in glucose tolerance have been demonstrated with experimental elevations of FFAs $(14,18-21)$ but not in all studies (22). Glucose disposal during a euglycemic clamp (clamp) falls during lipid/heparin infusions $(7,17)$. It remains a critical question, however, whether the reduced insulin-

1. Abbreviations used in this paper: $\mathrm{Ra}$, appearance rate; $\mathrm{BMI}$, body mass index; $\mathrm{CV}$, coefficient of variation; EGPR, endogenous glucose production rate; clamp, euglycemic clamp; FFM, fat-free mass; FFA, free fatty acid(s)/plasma FFA concentration; M, glucose disposal during hyperinsulinemia (used synonymously with insulin-mediated glucose disposal-see calculations in Methods); storage, nonoxidative glucose disposal; RQ, respiratory quotient; RQL, respiratory quotient for lipid oxidation-may vary depending on the particular lipid; excess $\mathrm{CO}_{2}$, total $\mathrm{CO}_{2}$ produced minus total $\mathrm{O}_{2}$ consumed; $\dot{\mathrm{V}} \mathrm{CO}_{2}$, carbon dioxide production; $\dot{\mathrm{VO}}_{2}$, oxygen consumption. 
mediated glucose disposal (M) found in many obese subjects is in fact related to changes in endogenous lipid metabolism.

This study combines the techniques of the clamp, indirect calorimetry, and labeled FFA infusion, allowing an examination of the relationships between insulin-mediated glucose disposal, carbohydrate oxidation and storage, and measures of lipid metabolism including FFA turnover and lipid oxidation. Subjects studied had a wide range of obesity, thus providing a range of lipid metabolic profiles and hence specifically avoiding the need to experimentally alter FFA metabolism.

\section{Methods}

Study subjects. 18 Southwest American Indian (Pima) women were selected to cover a wide range of obesity. All were studied in the Phoenix Clinical Research Section, after being stabilized for five or more days on a weight maintenance diet (45\% carbohydrate, $40 \%$ fat, $15 \%$ protein). All subjects were in good health as assessed with a medical history, physical examination, and routine hematological, biochemical, and urine tests. None were diabetic or had impaired glucose tolerance (23). Body composition was determined by underwater weighing (24) with simultaneous determination of residual lung volume. Calculation of percent fat was according to Keys and Brozek (25). These results were used to calculate fat mass and fat-free mass (FFM). All subjects gave informed consent and the studies were approved by the ethical committees of the National Institutes of Health and Indian Health Service, and by the Gila River Indian Community. Clinical data for the subjects are shown on Table I.

Experimental protocol. After at least $5 \mathrm{~d}$ on a standard diet and after an overnight fast of 13-14 h, measurement of FFA turnover was performed with simultaneous indirect calorimetry, followed by a clamp with simultaneous indirect calorimetry.

FFA turnover studies were performed using methods developed by Havel et al. (26). $1{ }^{14} \mathrm{C}$-palmitate (New England Nuclear, Boston, MA) was complexed to fatty acid poor human serum albumin (Sigma Chemical Co., St. Louis, MO) under sterile conditions. The labeled palmitate was evaporated to dryness, dissolved in $0.02 \mathrm{M} \mathrm{NaOH}$, and added dropwise to the stirring warmed albumin solution. The final preparation $\left(10 \mathrm{mg} / \mathrm{ml}\right.$ albumin, $0.5 \mu \mathrm{Ci}{ }^{14} \mathrm{C} / \mathrm{ml}, 2.3 \mathrm{mg}$ palmitate/ $\mathrm{ml}$ ) was infused at a rate of $0.5 \mathrm{ml} / \mathrm{min} .66 \mathrm{~min}$ before the start of the insulin infusion, a plasma sample was obtained for baseline FFA concentration, and ${ }^{14} \mathrm{C}$-palmitate infusion commenced. Beginning 35 min after the ${ }^{14} \mathrm{C}$-palmitate infusion commenced, four blood samples were drawn over $23 \mathrm{~min}$ for determination of FFA concentration and specific activity. These sampling times overlapped in part the sampling times for the preinsulin $\left[3-{ }^{3} \mathrm{H}\right] \mathrm{glucose}$. Previous reports suggested the FFA specific activity would be at a steady state at the time of blood collection in the above protocol $(26,27)$. In this study, the mean of the coefficients of variation (CV), calculated for each individual, of FFA specific activity was $7.3 \%$. Specific activity showed no significant change over the study period (change $=+4.1 \pm 2.5 \%)(P=0.11)$.

The clamp was performed by a modification of the method of DeFronzo et al. (28). At $0600 \mathrm{~h}$ and after the patient had voided an intravenous catheter was placed in an antecubital vein for infusion of insulin, glucose, $\left[3-{ }^{3} \mathrm{H}\right]$ glucose, and $1-{ }^{14} \mathrm{C}$-palmitate. Another catheter was placed retrograde in a dorsal vein of the contralateral hand for blood withdrawal. The hand was kept in a warming box at $70^{\circ} \mathrm{C}$. A primed, continuous infusion of $\left[3-{ }^{3} \mathrm{H}\right]$ glucose was then begun and continued throughout the procedure. After $2.5 \mathrm{~h}$, four plasma samples were obtained during a 30 -min period for $\left[3-{ }^{3} \mathrm{H}\right]$ glucose specific activity determinations. After $3 \mathrm{~h}$, primed continuous infusion of purified pork insulin (Velosulin; Nordisk-USA, Bethesda, MD) $\left(40 \mathrm{mU} / \mathrm{m}^{2}\right.$ per $\left.\mathrm{min}\right)$ was started. $5 \mathrm{~min}$ after the start of the insulin, a variable $20 \%$ glucose infusion was started to maintain the plasma glucose concentration at approximately the basal glucose level for the entire $100 \mathrm{~min}$ of hyperinsulinemia. Samples for plasma glucose concentration were obtained every $5 \mathrm{~min}$ throughout the test. Samples for plasma insulin and $\left[3-{ }^{3} \mathrm{H}\right]$ glucose specific activity were obtained every $10 \mathrm{~min}$ from 60 to $100 \mathrm{~min}$. Glucose and insulin levels during the clamp were: mean $( \pm \mathrm{SE}$ ) glucose $93.1 \pm 1.2 \mathrm{mg} / \mathrm{dl}$ (mean CV $2.5 \pm 0.1 \%$ ), and mean insulin $128 \pm 10 \mu \mathrm{U} / \mathrm{ml}$ (mean CV $4.1 \pm 0.6 \%$ ).

During the $1{ }^{14} \mathrm{C}$-palmitate infusion and throughout the insulin infusions, oxygen consumption and carbon dioxide production were determined by open circuit indirect calorimetry $(14,29)$. A transparent plastic hood was placed over the subject's head and secured around the neck with a soft collar. Room air was drawn through the hood at a rate of 25-40 liter/min. The flow rate was measured using a pneumotachograph attached to a Fleisch flow transducer (Gould Electronics \& Electrical Products, Cleveland, $\mathrm{OH}$ ). A constant fraction of the expired gases was withdrawn and analyzed for oxygen and $\mathrm{CO}_{2}$ concentrations. The oxygen was measured on a zirconium cell analyzer and the $\mathrm{CO}_{2}$ on an infrared analyzer (both from Applied Electrochemistry, Sunnyvale, CA). The analyzers and flow meter outputs were connected to a desk top computer (Hewlett Packard Co., Palo Alto, CA), which recorded continuous integrated calorimetric measurements over 5-min intervals. Nonprotein oxidation during the test was estimated using the urinary urea production rate. This was calculated as the urine urea concentration times urine volume times time since last voiding, on a specimen collected at the end of the clamp. The nonprotein respiratory quotient was then calculated and substrate oxidation values determined from the equations of Lusk (30).

Analytical methods. Plasma glucose concentration was measured by the glucose oxidase method using a Beckman glucose analyzer (Beckman Instruments Inc., Fullerton, CA). Plasma insulin concentrations were determined by the Herbert modification (31) of the radioimmunoassay of Yalow and Berson (32). The tritiated glucose specific activity in blood samples was measured as described previously by others (33) using perchloric acid to precipitate plasma proteins. FFAs were measured by a modification of the method of Soloni and Sardina (34) as described previously (35). The FFA assay was standardized by the inclusion of reference pools that were calibrated using the titration method of Dole (36) as modified by Trout et al. (37). All samples for fatty acid determination were collected in tubes containing paraoxon $(1.1 \mathrm{mg} / 2 \mathrm{ml})$ and kept on ice at all times. FFA concentration and radioactivity were determined after the plasma was extracted with 10 $\mathrm{ml}$ isopropanol/heptane $/ \mathrm{H}_{2} \mathrm{SO}_{4}$ (ratio 40:10:1), $6 \mathrm{ml}$ heptane and $4 \mathrm{ml}$ $\mathrm{H}_{2} \mathrm{O}$ were added, and fatty acids were isolated from the lipid extract using $0.02 \mathrm{~N} \mathrm{NaOH}$ and reextracted using acidified heptane.

Calculations. Substrate oxidation rates were calculated according to published methods $(14,29,30,38,39)$ (for exceptions see Appendix). The following constants were used: $6.25 \mathrm{~g}$ of protein were oxidized to produce $1 \mathrm{~g}$ of urea nitrogen, and $966.3 \mathrm{ml}$ of $\mathrm{O}_{2}$ were required to oxidize $1 \mathrm{~g}$ of protein in this way, producing $773.9 \mathrm{ml}$ of $\mathrm{CO}_{2}$. The respiratory quotient $(\mathrm{RQ})$ for oxidation of lipid is 0.707 and for carbohydrate 1.000 . Oxygen consumed is $2019.3 \mathrm{ml} / \mathrm{g}$ of fat, 828.8 $\mathrm{ml} / \mathrm{g}$ of glycogen, and $745.8 \mathrm{ml} / \mathrm{g}$ of glucose. The constants for glycogen were used for calculations in the basal state. During the clamp, the constants for glucose were used. It should be noted that the constants used for lipid oxidation were those for the consumption of whole fat. Since this contained glycerol, the fatty acid oxidation (in milligrams) was overestimated. The difference would, however, be $<4 \%$ if pure palmitate $(R Q=0.696)$ and $<1 \%$ if pure oleate $(R Q=0.706)$ were assumed to be oxidized. Lipid oxidation in milligrams was converted to moles using the molecular weight of palmitic acid, so that the data for turnover and oxidation could be compared directly.

The basal and insulin stimulated carbohydrate oxidation rates and lipid oxidation were calculated from the indirect calorimetric data by averaging the data for $40 \mathrm{~min}$ before the beginning of the insulin infusion and for the last $40 \mathrm{~min}$ during the insulin infusion. The carbohydrate storage rate was estimated by subtracting the carbohydrate oxidation rate from the total glucose disposal rate (see below) during the insulin infusions.

If the $R Q$ was $>1.00$ then the calculated lipid oxidation assumes a 


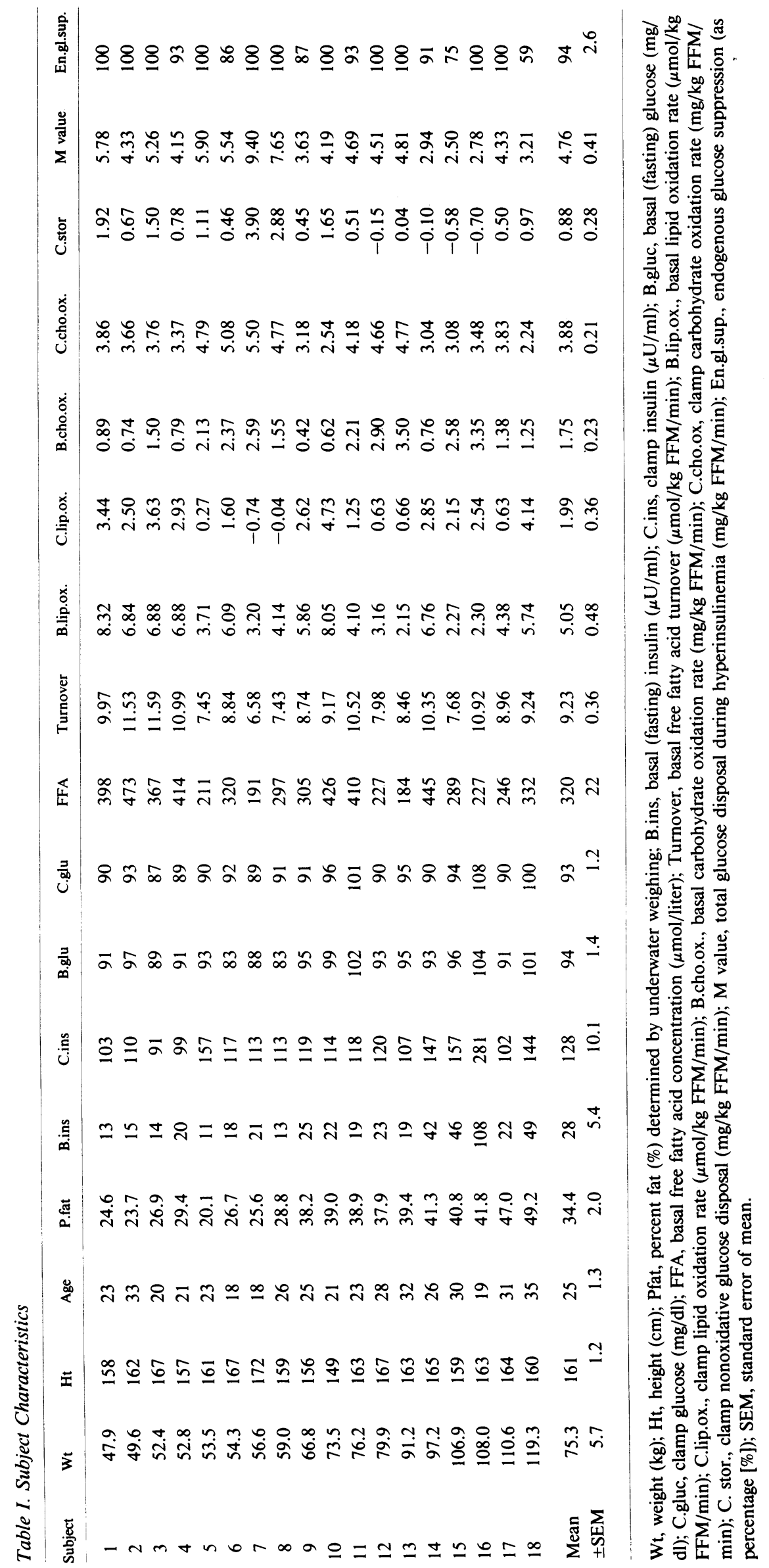


negative value. Since lipid synthesis produces more $\mathrm{CO}_{2}$ than oxygen consumed on a molar basis, it was assumed that an $R Q>1.00$ implies net lipid synthesis. The amount of lipid synthesized from glucose for an $R Q>1.000$ was taken as the absolute value of the lipid oxidation as suggested by Frayn (39) (see Appendix). The amount of glucose this represents can be calculated using the constants already noted, and this was included in the value for nonoxidized or stored glucose. In those two subjects where the RQ exceeded 1.000 during the insulin infusion, oxidation of glucose was calculated as the glucose oxidation rate by the equations of Lusk (30), less the glucose assumed to be going into lipid synthesis (see Appendix). Storage was then calculated as above.

The appearance rate $(\mathrm{Ra})$ of glucose in the plasma was calculated from the plasma $\left[3-{ }^{3} \mathrm{H}\right]$ glucose specific activities using the equations of Steele (40). In the resting, postabsorptive state the Ra, calculated from Steele's (40) steady state equation, was equal to the endogenous glucose production rate (EGPR), since there was no exogenous glucose infusion. During the clamp, the EGPR equaled the difference between the exogenous glucose infusion rate and the Ra calculated using Steele's (40) non-steady state equations (EGPR equals Ra minus exogenous glucose infusion rate). An effective volume of distribution of glucose of $100 \mathrm{ml} / \mathrm{kg}$ was assumed. The coefficient of variation of glucose specific activity during the clamp was calculated on each individual. The mean CV for all 18 subjects was $6.8 \pm 1.4 \%$. When the Ra equaled the exogenous glucose infusion rate, the EGPR is assumed to be completely suppressed, so that the total glucose disposal rate equals the exogenous glucose infusion rate. The insulin-mediated glucose disposal, as we have described it, was in part due to glucose uptake in noninsulin-dependent tissues as well as that in insulin-dependent tissues. We use the term here in the limited sense, therefore, of glucose disposal during hyperinsulinaemia. These data were calculated for each 20 -min period between 60 and 100 min during the clamp, and then averaged to calculate the total glucose disposal, or $M$ value. Rate of turnover of FFA was calculated assuming a steady state as (26) (infusion rate $[\mathrm{dpm} / \mathrm{min}]) /($ specific activity $[\mathrm{dpm} / \mu \mathrm{mol}])$. In this instance, turnover equals rate of appearance equals rate of disappearance of FFAs. Turnover is given in Results as $\mu \mathrm{mol} / \mathrm{kg} \mathrm{FFM} / \mathrm{min}$ unless otherwise stated.

Statistical methods. All statistical calculations were performed using standard programs of the SAS Institute-Statistical Analysis System, Cary, NC. Unless otherwise stated, whole body metabolic measures were divided by the FFM, since FFM was considered the best measure of metabolic cell mass (25) available to us. All correlations were Pearson product-moment correlations.

\section{Results}

Basal studies (Table II, Figs. 1-3). The relationship between plasma FFA, FFA turnover, and basal lipid oxidation is illustrated in Figs. 1 and 2. Plasma FFA concentration was significantly correlated with FFA turnover and the basal lipid oxidation. A partial correlation analysis of FFA concentration and basal lipid oxidation rate showed a significant correlation of the two variables independent of the turnover $(r=0.73, P$ $<0.001$ ). A further dissociation of the turnover rate from plasma FFA and basal lipid oxidation was demonstrated by the fact that FFA turnover in micromoles per minute significantly correlated with the FFM $(r=0.77, P<0.0002)$, but lipid oxidation in micromoles per minute and FFA concentration in micromoles per liter were not related to the FFM ( $r$ $=-0.10, P=0.7$, and $r=-0.35, P=0.1$, respectively). The turnover exceeded the lipid oxidation in every case with the ratio (turnover/lipid oxidation) ranging from 1.1 to 4.9 (mean 1.9). Basal lipid oxidation and basal carbohydrate oxidation were significantly negatively correlated as illustrated in Fig. 3.

Table II. Simple Correlations of Metabolic Data on 18 Southwest American Indian Females

\begin{tabular}{|c|c|c|c|c|c|c|c|c|}
\hline & FFA & Turnover & B.lip.ox. & C.lip.ox. & B.cho.ox. & C.cho.ox. & C.stor & M value \\
\hline Turnover & $\begin{array}{r}0.69^{*} \\
<0.002\end{array}$ & & & & & & & \\
\hline B.lip.ox. & $\begin{array}{c}0.81 \\
\leq 0.0001\end{array}$ & $\begin{array}{r}0.52 \\
<0.03\end{array}$ & & & & & & \\
\hline C.lip.ox. & $\begin{array}{c}0.67 \\
<0.003\end{array}$ & $\begin{array}{c}0.64 \\
<0.005\end{array}$ & $\begin{array}{c}0.70 \\
<0.002\end{array}$ & & & & & \\
\hline B.cho.ox. & $\begin{array}{l}-0.74 \\
<0.0005\end{array}$ & NS & $\begin{array}{l}-0.85 \\
\leq 0.0001\end{array}$ & $\begin{array}{l}-0.56 \\
<0.02\end{array}$ & & & & \\
\hline C.cho.ox. & $\begin{array}{l}-0.54 \\
<0.03\end{array}$ & $\begin{array}{l}-0.47 \\
<0.05\end{array}$ & NS & $\begin{array}{l}-0.85 \\
\leq 0.0001\end{array}$ & $\begin{array}{r}0.56 \\
<0.02\end{array}$ & & & \\
\hline C.stor & NS & NS & NS & NS & NS & NS & & \\
\hline $\mathbf{M}$ value & NS & $\begin{array}{l}-0.48 \\
<0.05\end{array}$ & NS & $\begin{array}{l}-0.60 \\
<0.01\end{array}$ & NS & $\begin{array}{c}0.77 \\
<0.0005\end{array}$ & $\begin{array}{c}0.87 \\
\leq 0.0001\end{array}$ & \\
\hline Pfat & NS & NS & NS & NS & NS & $\begin{array}{l}-0.56 \\
<0.02\end{array}$ & $\begin{array}{l}-0.52 \\
<0.03\end{array}$ & $\begin{array}{l}-0.64 \\
<0.004\end{array}$ \\
\hline BMI & NS & NS & NS & NS & NS & $\begin{array}{l}-0.57 \\
<0.02\end{array}$ & $\begin{array}{l}-0.54 \\
<0.03\end{array}$ & $\begin{array}{l}-0.66 \\
<0.003\end{array}$ \\
\hline
\end{tabular}

${ }^{*} r$ values given above $P$ values for Pearson product-moment correlations; $P$ values $>0.05$ were given as nonsignificant (NS). B.lip.ox., basal lipid oxidation rate ( $\mu \mathrm{mol} / \mathrm{kg} \mathrm{FFM} / \mathrm{min})$; C.lip.ox., clamp lipid oxidation rate $(\mu \mathrm{mol} / \mathrm{kg} \mathrm{FFM} / \mathrm{min})$; B.cho.ox., basal carbohydrate oxidation rate ( $\mathrm{mg} / \mathrm{kg} \mathrm{FFM} / \mathrm{min}$ ); C.cho.ox., clamp carbohydrate oxidation rate ( $\mathrm{mg} / \mathrm{kg} \mathrm{FFM} / \mathrm{min}$ ); C.stor, clamp nonoxidative glucose disposal (mg/kg FFM/ $\mathrm{min}$ ); $\mathrm{M}$ value, total glucose disposal during hyperinsulinemia ( $\mathrm{mg} / \mathrm{kg} \mathrm{FFM} / \mathrm{min})$; Pfat, percent fat (\%) determined by underwater weighing; BMI, weight $(\mathrm{kg}) /$ height $\left(\mathrm{M}^{2}\right)$. 


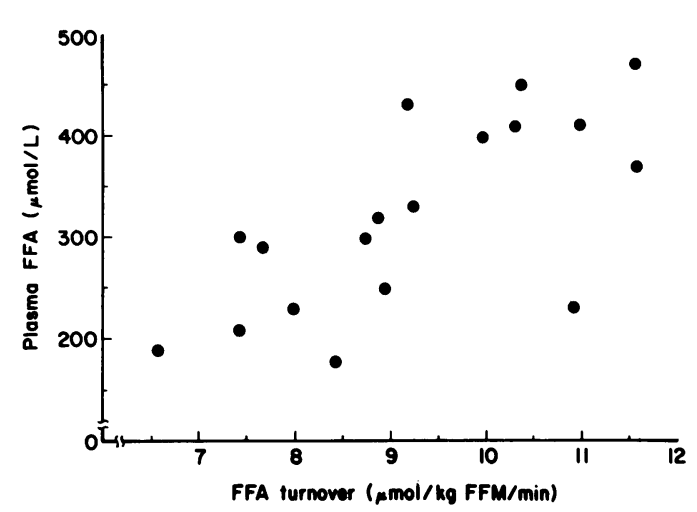

Figure 1. The relationship of basal FFA concentration and basal FFA turnover measured by $1-{ }^{14} \mathrm{C}$-palmitate infusion $(r=0.69, P<0.002)$.

FFA concentration and basal carbohydrate oxidation were also negatively correlated.

Lipid and carbohydrate oxidation-euglycemic clamp (Table II Figs. 3 and 4). During insulin administration, lipid oxidation fell and carbohydrate oxidation rose. The decrease in lipid oxidation correlated with the increase in carbohydrate oxidation ( $r=0.96, P \leq 0.0001$ ) (Fig. 4). During the clamp, as in the basal state, the lipid oxidation negatively correlated with the carbohydrate oxidation (Fig. 3).

Both clamp lipid and carbohydrate oxidation were correlated with the basal plasma FFA, and FFA turnover, basal lipid oxidation and basal carbohydrate oxidation rates (Table II).

$M$ value (Table II, Fig. 5). During the insulin administration the $M$ value was significantly correlated with the glucose oxidation rate. The difference between these two measures, the nonoxidative glucose disposal (storage), also correlated with the $M$ value. The relationship between these three measures is represented in Fig. 5. In four individuals, glucose oxidation actually exceeded the $M$ value, giving negative storage rates. The ratio of oxidation to total glucose uptake expressed as a percentage, therefore, ranged from 59 to $125 \%$. The ratio of storage to oxidation increased with increasing $\mathrm{M}$ value $(r$ $=0.69, P<0.002$ ).

The $M$ value was significantly correlated with a number of measures of lipid metabolism, though this was mainly with those measures taken during the insulin administration. Lipid oxidation during the clamp was significantly negatively correlated with the $M$ value. However, while lower lipid oxidation rates were associated with higher glucose oxidation rates (vide supra), there was no correlation of lipid oxidation with glucose storage $(r=-0.22, P=0.4)$. There is little effect on any relationship if negative storage rates are assumed to be zero

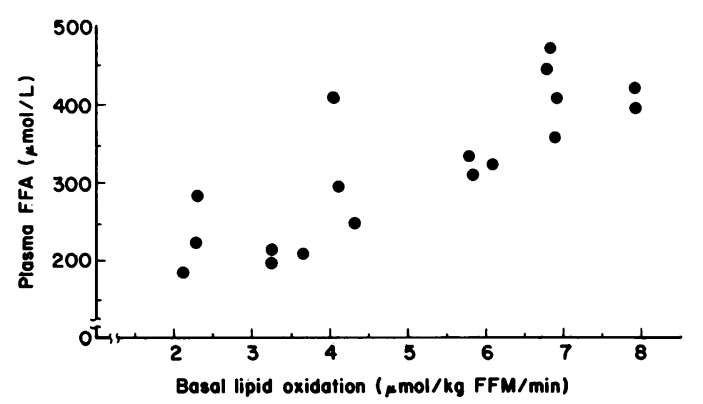

Figure 2. The relationship of basal FFA concentration and basal lipid oxidation measured by indirect calorimetry $(r=0.81, P \leq 0.0001)$.

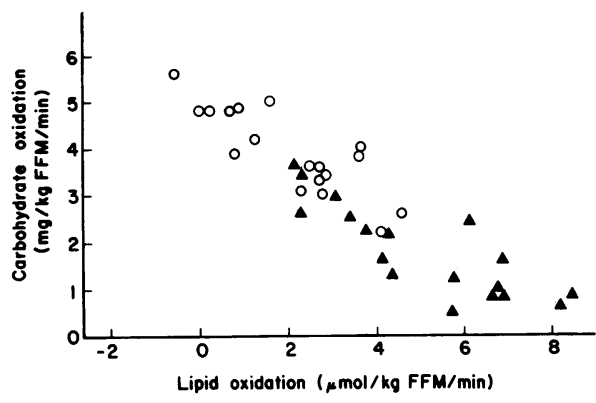

Figure 3. Relationship of basal lipid oxidation to basal carbohydrate oxidation (solid triangles) and relationship of clamp lipid oxidation to clamp carbohydrate oxidation (open circles) measured by indirect calorimetry (for basal, $r=-0.85, P \leq 0.0001$, for clamp, $r=-0.85$, $P \leq 0.0001$ ).

storage. Basal FFA turnover was negatively correlated with $\mathbf{M}$, but FFA concentration and basal lipid oxidation were not correlated with $\mathrm{M}(r=-0.29, P=0.2, r=0.07, P=0.8$, respectively). The effect of insulin in decreasing lipid oxidation rates was calculated in two ways: firstly, as the decrease in lipid oxidation from the basal state (B. lip. ox. - C. lip. ox.); secondly, this decrease as it related to the lipid oxidation rate before insulin was given, i.e., the percent suppression of the lipid oxidation from the basal state ([B. lip. ox. - C. lip. ox.] $\times 100 /[$ B. lip. ox.]). These were both correlated with the $\mathbf{M}$ value $(r=0.54, P<0.02$, and $r=0.82, P \leq 0.0001$, respectively).

Effect of obesity (Table II). The $\mathbf{M}$ value, clamp glucose oxidation, and clamp glucose storage were negatively correlated with obesity expressed as percent body fat (fat mass/total weight) or body mass index (BMI) (weight $[\mathrm{kg}] / \mathrm{height}^{2}\left[\mathrm{~m}^{2}\right]$ ). Degree of obesity was also correlated with the decrease in lipid oxidation from basal to clamp $(r=-0.59, P<0.01, r$ $=-0.72, P<0.001$ for percent fat and BMI, respectively). Percent suppression of lipid oxidation from the basal state to the clamp correlated with BMI $(r=-0.58, P<0.02)$ and weakly with percent fat $(r=-0.47, P<0.05)$. Neither measure of obesity showed a significant association with plasma FFAs $(r=-0.10, P=0.7, r=-0.19, P=0.4)$, basal turnover $(r$ $=0.03, P=0.9, r=-0.05, P=0.83$ ), basal lipid oxidation ( $r=-0.25, P=0.3, r=-0.4, P=0.1)$, or clamp lipid oxidation $(r=0.23, P=0.4, r=0.21, P=0.4)(r$ and $P$ values given for percent fat and BMI, respectively). If percent desirable weight is used as an index of obesity, the correlations

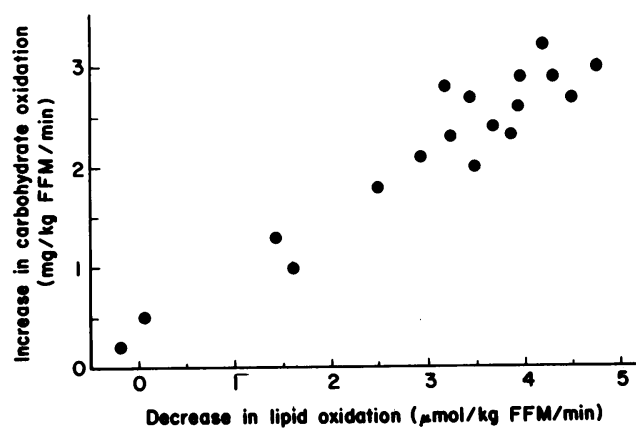

Figure 4. The relationship of the increase in carbohydrate oxidation and the decrease in lipid oxidation resulting from the insulin administration of the clamp as measured by indirect calorimetry $(r=0.96$, $P \leq 0.0001$ ). 


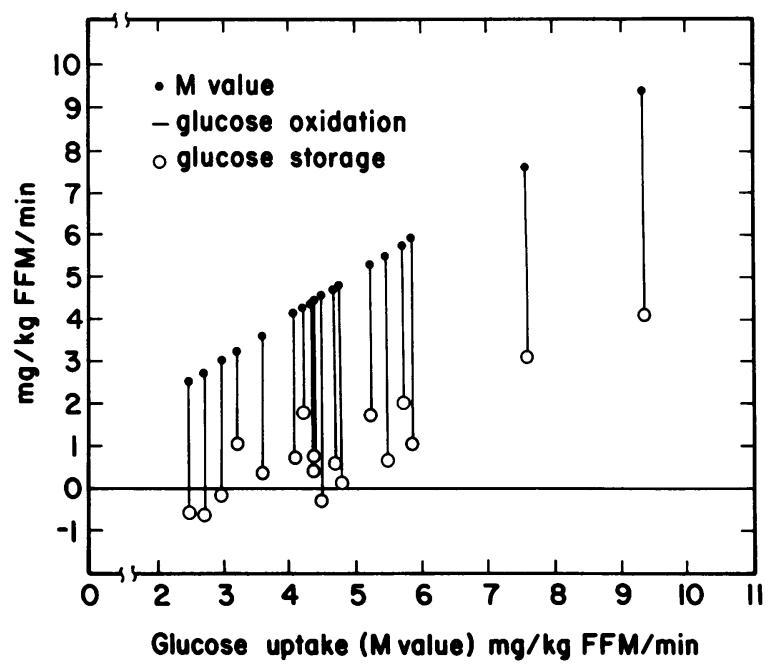

Figure 5. Relationship of glucose uptake (M), glucose oxidation, and glucose storage during the clamp. For each subject the values of $\mathbf{M}$ (closed circles) and glucose storage (open circles) are plotted on the vertical axis according to the $M$ shown on the horizontal axis. Thus the closed circles $(\mathrm{M})$ lie on the line of identity. Glucose oxidation, which is the difference between $M$ and storage, is shown by the vertical line segment connecting the points for $M$ and storage. $M$ was measured by a clamp, and glucose oxidation was measured by simultaneous indirect calorimetry. Storage is calculated from the difference between $\mathbf{M}$ and oxidation. A simple linear regression of storage on $\mathbf{M}$ predicts an increase in storage of $5.9 \mathrm{mg} / \mathrm{kg} \mathrm{FFM} / \mathrm{min}$ for $10 \mathrm{mg} / \mathrm{kg}$ $\mathrm{FFM} / \mathrm{min}$ increase in $\mathrm{M}$. The regression value for oxidation is 4.1 $\mathrm{mg} / \mathrm{kg} \mathrm{FFM} / \mathrm{min}$ for $10 \mathrm{mg} / \mathrm{kg} \mathrm{FFM} / \mathrm{min}$ increase in $\mathrm{M}$.

are almost identical to those found using the body mass index (data not shown).

\section{Discussion}

Basal studies. Our findings are consistent with numerous reports which suggest that the plasma FFA concentration or the tissue presentation rate of FFA (concentration times blood flow) are regulators of lipid oxidation. These reports include data on whole body lipid oxidation (41), liver and muscle uptake $(27,42,43)$, and liver ketogenesis (44). In discussing the metabolism of FFAs it should be noted that FFA metabolism includes the production and oxidation of ketones-the uptake of ketones being proportional to their availability (4, 45). Our studies do not distinguish between sites or intermediate steps in lipid oxidation. When compared with the lipid oxidation rates, the FFA turnover (rate of appearance/disappearance), at least by the techniques we employ, appears to be more complex than a simple transport of FFA from storage sites to oxidation sites. That not all of the FFA turnover leads to oxidation is consistent with other reports (46). The rapid cycling in fat cells of FFA and triglycerides (47) could potentially explain the nonoxidative disposal of the FFA turnover.

Since it is the oxidation rather than the presence of FFA and ketones that provide a mechanism for regulating the glucose oxidative pathway, it is the lipid oxidation rather than total FFA disappearance that is critical to the glucose fatty acid cycle hypothesis. Basal carbohydrate oxidation was negatively correlated with basal FFA concentration and basal lipid oxidation, which was consistent with other reports $(12,13)$. The values for basal glucose oxidation are similar to those reported by others $(48,49)$.
There is an obligatory uptake and oxidation of glucose in certain tissues-particularly the central nervous system. This suggests that in some of our subjects the glucose oxidized in other tissues must be extremely low. This effect of sparing glucose for the central nervous system has been discussed previously (3). Ketones (but not FFA) can cross the blood brain barrier and inhibit glucose oxidation (4), so that even this glucose-using organ is potentially subject to regulation, at least in part, by lipid metabolism. We interpret these basal data as consistent with the reports suggesting that FFA availability, as expressed by the plasma concentration, is a regulator of lipid oxidation, and this in turn could regulate carbohydrate oxidation.

Lipid and carbohydrate oxidation-euglycemic clamp. During hyperinsulinemia, the lipid oxidation rate fell in all but one subject. This was most likely due to a fall in FFA concentrations, since insulin suppresses FFA appearance rate and plasma concentrations (50-52). Insulin action on FFA release is presumably by an action on hormone sensitive lipase (53) or a direct intracellular effect of glucose (54). Since clamp lipid oxidation was correlated with basal FFA concentration and basal lipid oxidation, the data suggest that differences between individuals in the regulation of FFA levels and lipid oxidation persist during insulin administration. There is one report on FFA turnover and insulin infusions that supports this suggestion (55). Available data suggest that while FFA suppression is very sensitive to insulin, the resulting FFA levels need not be the same in all subjects $(51,52)$. The carbohydrate oxidation rose during the insulin administration. Furthermore, the increase from the basal state in carbohydrate oxidation was well correlated with the decrease from basal in lipid oxidation (Fig. 4). In Fig. 3, the nonprotein energy expenditure for each data point is the sum of the values on each axis (if the values are converted to calories). Therefore, the distance of each point from the origin is proportional to the nonprotein energy expenditure. In Fig. 3, the $\mathrm{CV}$ of calories derived from carbohydrate plus lipid was $12 \%$, but the CV of carbohydrate oxidation was $51 \%$ and of lipid oxidation $67 \%$ when all data points were considered. If the energy expenditure from lipid plus carbohydrate oxidation were to vary widely, then the correlations we demonstrate would be lost. This demonstrates that energy balance is confined to much narrower limits than is the oxidation of carbohydrate or lipid. This presumably reflects some form of regulatory mechanism in energy metabolism and illustrates the importance of understanding mechanisms that might link lipid and carbohydrate oxidation.

In this study, subjects were studied at, or close to their basal (euglycemic) glucose level but with hyperinsulinemia. Hence, the increase in glucose oxidation and the decrease in lipid oxidation were insulin-mediated effects rather than effects of glucose per se. To explain the relationships demonstrated between lipid and carbohydrate oxidation, two alternate explanations are possible. (a) Insulin acts directly to increase glucose oxidation and acts directly to decrease lipid oxidation, but the two phenomena are unrelated; $(b)$ insulin acts to change the substrate oxidation rates but the effect of insulin on both systems is modulated by an interaction of the two oxidative systems.

Insulin can increase glucose oxidation by increasing intracellular glucose availability and hence stimulating glycolysis (56). Definitive evidence for activation of pyruvate dehydrogenase under these circumstances is lacking, though there is suggestive evidence (2). It seems reasonable to ask, therefore, 
if increased glucose uptake will naturally result in increased glucose oxidation.

In a report by Jacot et al. (57) using indirect calorimetry with steady state glucose and insulin infusions, increasing glucose uptake by insulin infusion or hyperglycemia increased storage but did not increase glucose oxidation. In a report by Thiebaud et al. (16), using similar techniques but with the addition of lipid infusions, several of their study groups had similar glucose oxidation rates but differing glucose uptake rates. In an in vitro study reported by Maizels et al. (9), glucose uptake and oxidation was compared in isolated soleus muscle. Addition of insulin and acetoacetate increased glucose uptake and lactate production but did not change glucose oxidation. These latter two studies were not analyzed with the particular questions we are raising in mind, however, so caution needs to be exercised in making these interpretations. It is also interesting to note several reports which demonstrated that the lactate production across a limb is well correlated with the FFA uptake or ketone availability $(43,45)$. These latter reports are consistent with the hypothesis that stimulation of glycolysis under circumstances of increased FFA uptake or metabolism could result in lactate production rather than $\mathrm{CO}_{2}$ production from glucose.

In a study reported by Wolfe et al. (58), the infusion of glucose or glucose plus insulin failed to increase total glucose oxidation or to decrease the lipid oxidation rate, as evidenced by a lack of change in total $\dot{\mathrm{V}} \mathrm{O}_{2}, \dot{\mathrm{V}} \mathrm{CO}_{2}$, and $\mathrm{RQ}$. There was, however, a progressive increase in the contribution of the labeled exogenous glucose load to the expired $\mathrm{CO}_{2}$ as the glucose uptake increased. The alteration of the relative contributions of exogenous and endogenous glucose to the total carbohydrate oxidation with increasing glucose loads has also been demonstrated by Mosora et al. (59) in somewhat differently designed studies. Both these studies suggest that under some circumstances the size of a glucose load will determine how much of the body's glucose stores will be oxidized or spared after a glucose load rather than how great the total glucose oxidation rate will be.

On the basis of the known effect of FFAs or ketones on glucose oxidation, we suggest, therefore, that the effect of insulin on glucose oxidation cannot be simply due to increased glucose uptake. Nevertheless, the effects of glucose uptake on the suppression of lipolysis and the stimulation of glycolysis and pyruvate oxidation might further increase both the fall in FFA concentrations and the consequent activation of pyruvate dehydrogenase brought about by insulin. Mechanism (b) (above), therefore, appears to best explain the known physiology, but a contribution of mechanism (a) cannot be excluded.

Because of the nature of this study, causal conclusions cannot be drawn from the demonstrated correlations. On the basis of the literature already cited, however, our data are consistent with the following hypothesis: Basal FFA concentration, regulated by whatever mechanisms, regulates the basal lipid oxidation rate, which in turn regulates basal carbohydrate oxidation rates. During insulin administration, the interindividual differences in FFA availability persist, but plasma levels fall. This leads to a fall in the lipid oxidation rates, which in turn allows carbohydrate oxidation rates to rise. Insulin's effect on glucose oxidation under this hypothesis would be indirect, as suggested by others $(2,3)$, or at best partially indirect (via FFA regulation), and partially permissive/regulatory (by increasing intracellular availability of glucose).
Insulin-mediated glucose disposal. Indirect calorimetry allowed carbohydrate oxidation during the clamp to be measured simultaneously with the glucose uptake measurements. The difference between glucose oxidation and glucose disposalthe nonoxidative glucose disposal, is a measure of glucose storage $(60,61)$. This measures, however, only the minimum glucose storage. It is quite possible that infused glucose could be stored while previously stored glycogen is oxidized, as suggested by studies comparing the rate of glucose oxidation from labeled glucose loads by measurement of expired labeled $\mathrm{CO}_{2}$ and the rate of glucose oxidation by indirect calorimetry $(59,62)$. In some individuals with lower $M$ values in this study, the glucose oxidation equaled or actually exceeded the total glucose uptake. This may simply be due to the limitations of the techniques. It is quite possible, however, that glucose oxidation rates, if regulated at least partially by lipid oxidation rates, could exceed total glucose uptake, since the oxidized glucose would not need to come from the infused glucose but from glycogen stores. If glucose oxidation were always to equal glucose uptake then glycogen accumulation could not occur. In the free living situation, however hyperglycemia promotes glucose uptake (and presumably therefore glycogen accumulation) in part independently of insulin's action (63).

Glucose storage rates were not correlated with lipid oxidation, even though glucose oxidation and the $M$ value were, which suggests that storage and oxidation might be regulated differently. There are a number of published reports suggesting a dissociation of the processes of storage and oxidation (48, $49,64,65$ ). Hence, an impairment of storage or oxidation appears at different stages in the progression to a florid diabetic state (64), and disappears at different stages in the reversal of the disturbed metabolic state during treatment of diabetes $(49$, $65)$. Furthermore, glucose oxidation appears to reach a plateau under conditions in which glucose uptake or storage can still increase (48).

Glucose storage was $\sim 4.1 \mathrm{mg} / \mathrm{kg}$ FFM/min greater at the upper extreme of $\mathbf{M}$ values than at the lower extreme (refer to Fig. 5 legend). Glucose oxidation was $\sim 2.8 \mathrm{mg} / \mathrm{kg} \mathrm{FFM} / \mathrm{min}$ greater over the same range. Hence, if glucose oxidation makes a contribution to producing high $\mathbf{M}$ values, it can only make a partial contribution, since significant changes in storage are also contributing to the difference between those with in vivo insulin sensitivity and resistance. These results are consistent with reports emphasizing the importance of glucose storage in total glucose disposal $(64,65)$. One report has demonstrated that glucose storage as well as glucose oxidation rates can be reduced by raising FFA levels (17). The relationship between these studies in normal lean males using lipid/heparin infusions and our studies in spontaneously insulin resistant females remains to be determined.

During the administration of insulin, two separate but possibly interrelated processes may occur (see reference 3 ). Insulin stimulates glucose uptake in muscle (60) by stimulating membrane transport and/or by stimulating glycogen synthase activity (61). Insulin also suppresses plasma FFAs, which decreases lipid oxidation and increases carbohydrate oxidation. This increase in carbohydrate oxidation, however, only makes a partial contribution, at best, to the total insulin-mediated glucose uptake. Some recent reports have emphasized the role of muscle in glucose storage (66) and liver in glucose oxidation (67) after an oral glucose load. The firm establishment of this hypothesis requires further study. 
Lipid oxidation rates during the clamp (but not the basal lipid oxidation) were significantly correlated with the $M$ value. We suggest that this is in part due to the fact that the suppression of FFAs is insulin mediated. The correlation of the decrease in lipid oxidation from basal and the percent suppression of lipid oxidation from basal with the $M$ value supports this view.

Degree of obesity, expressed as either percent fat, BMI, or percent desirable weight was not correlated with the basal plasma FFAs. Dole (36) found a correlation of FFAs with a ratio of actual weight/normal weight as an index of obesity and Opie and Walfish (68) had similar findings. Bjorntorp et al. (69), however, found no significant relationship of plasma FFA to body fat/body cell mass ratio as an index of obesity. The reason for these discrepant findings are not clear. We also found no correlation of the degree of obesity with basal lipid oxidation, basal turnover, or clamp lipid oxidation. The percent suppression of lipid oxidation from basal is weakly negatively correlated with BMI and percent fat but strongly negatively correlated with $M$ value. The change in lipid oxidation from the basal state does negatively correlate with obesity and $M$ value. We conclude, therefore, that the relationship that exists between the $M$ value and degree of obesity is not due to changes in lipid metabolism, since $M$ and obesity relate to lipid metabolism either in different ways or not at all.

We conclude that an interaction of lipid and glucose metabolism as proposed by Randle et al. (1) may be operative in the studies we have performed. The disposal of glucose, however, has two components. The storage component does not appear to be associated with lipid oxidation in the way that the oxidative component is. Since the results show that the glucose storage component is of at least equal importance to oxidation in distinguishing between those with low and high $M$ values, we suggest that the glucose fatty acid cycle can only partially explain impaired in vivo insulin-mediated glucose disposal. The impact of obesity on in vivo insulin resistance appears to be mediated by factors other than changes in lipid availability or metabolism. Investigations on potential sites and mechanisms of glucose storage rather than oxidation may provide important insights into the nature of impaired in vivo insulin action, and the metabolic impact of obesity on glucose metabolism.

\section{Appendix}

The purpose of the following discussion is to show that for $R Q$ $>1.00$, the absolute value of the calculated value of lipid oxidation is equivalent to lipid synthesis, and to show that for $R Q>1.00$, the calculated value for carbohydrate oxidation overestimates the conversion of glucose to $\mathrm{CO}_{2}$ by the amount of glucose converted to lipid (and hence stored).

The Lusk equations can be used to calculate the relative distribution of oxygen between lipid and carbohydrate oxidation. When the RQ exceeds 1.00, however, the methods for calculating lipid synthesis and glucose conversion to lipid or $\mathrm{CO}_{2}$ are not as clear. The following is an explanation of the calculations we have used. They are not affected by the fact that lipid oxidation and synthesis may continue together, i.e., they only assume the net reaction. Furthermore, these equations cannot be used to determine the stoichiometry or RQ of lipid synthesis. This discussion deals only with nonprotein oxidation, i.e., the $R Q$ used here is the nonprotein RQ.

The following discussion does assume that if glucose is oxidized to $\mathrm{CO}_{2}$ or if glucose is first converted to lipid and then fully oxidized to $\mathrm{CO}_{2}$, that the total $\mathrm{CO}_{2}$ produced and $\mathrm{O}_{2}$ consumed will be the same, i.e., that the end products of glucose oxidation are independent of the mechanism of the reaction. Hydrogen and water have been left out of the following equations for the sake of simplicity, but it is assumed that the production of water would also be the same whichever pathway glucose followed in its oxidation. Excess $\mathrm{CO}_{2}$ is defined as the difference between the total $\mathrm{CO}_{2}$ produced in moles and the total $\mathrm{O}_{2}$ consumed in moles (excess $\mathrm{CO}_{2}$ ). Excess $\mathrm{O}_{2}$ is similarly defined.

In moles:

(y) glucose $+(a) \mathrm{O}_{2} \rightarrow(a) \mathrm{CO}_{2}$;

(y) glucose $+(b) \mathrm{O}_{2} \rightarrow(z)$ lipid $+(d) \mathrm{CO}_{2}$;

then $(z)$ lipid $+(e) \mathrm{O}_{2} \rightarrow(f) \mathrm{CO}_{2}$.

If Eq. 1 and Eqs. 2/2a are equivalent, then

$(a)=(b)+(e)=(d)+(f)$,

and $(d)-(b)=(e)-(f)$.

From Eqs. 2-4 it can be seen that the excess $\mathrm{CO}_{2}$ produced in the synthesis of $(z)$ moles of fatty acid (i.e., $[d]-[b])$ equals the excess of $\mathrm{O}_{2}$ (i.e., $\left.[e]-[f]\right)$ in the oxidation of $(z)$ moles of the same fatty acid. From Eqs. 2/2a, the respiratory quotient of lipid oxidation $(R Q L)$ :

$=(f) /(e)$;

$(R Q L) \times(e)=(f)$

$R Q L$ is a constant for any given lipid and $(e)$ is a constant for any given (z).

In lipid oxidation. Excess moles $\mathrm{O}_{2} /$ moles lipid carbon $=([e]$ $-[f]) /([f]) ;=([e]-R Q L \times[e]) /(R Q L \times[e]) ;$

$=([1-R Q L]) /(R Q L)$.

Excess moles $\mathrm{O}_{2} /$ mole of lipid

$=([1-R Q L] \times[f]) /([R Q L]) \times([z])$,

where $(f) /(z)$ are the moles of carbon per mole of lipid.

In lipid synthesis.

Excess moles $\mathrm{CO}_{2} /$ mole of lipid carbon $=([1-R Q L]) /([R Q L])$.

Excess moles $\mathrm{CO}_{2} /$ mole lipid synthesized

$=([1-R Q L] \times[f]) /([R Q L] \times[z])$.

For a lipid of a given composition, Eqs. 7a and $8 \mathrm{a}$ are constants which we will denote by the letter $K$.

Derivation of Lusk equations for lipid if $R Q>1.00$. Consider the simultaneous reactions:

glucose $+\mathrm{O}_{2} \rightarrow \mathrm{CO}_{2}$

glucose $+\mathrm{O}_{2} \rightarrow$ lipid $+\mathrm{CO}_{2}$

$\mathrm{RQ}=\left(\right.$ total $\left.\mathrm{CO}_{2}\right) /\left(\right.$ total $\left.\mathrm{O}_{2}\right)=\left(\dot{\mathrm{V}} \mathrm{CO}_{2}\right) /\left(\dot{\mathrm{V}}_{2}\right)$;

$\dot{\mathrm{V}} \mathrm{CO}_{2}=\left(\mathrm{RQ} \times \dot{\mathrm{V}}_{2}\right)$

excess $\mathrm{CO}_{2}=\left(\mathrm{RQ} \times \dot{\mathrm{V}} \mathrm{O}_{2}\right)-\left(\dot{\mathrm{V}}_{2}\right)$,

$=\left(\dot{\mathrm{V}} \mathrm{O}_{2}\right) \times(\mathrm{RQ}-1)$ $(K)$

Using Eqs. $8 a$ and 12. Moles of lipid synthesized $=\left(\right.$ excess $\left.\mathrm{CO}_{2}\right) /$

$=\left(\left[\dot{\mathrm{V}} \mathrm{O}_{2}\right] \times[\mathrm{RQ}-1]\right) /(K)$.

It can be similarly shown that for $\mathrm{RQ}$ of $<1.00$, moles of lipid oxidized

$=\left(\left[\dot{\mathrm{VO}}_{2}\right] \times[1-\mathrm{RQ}]\right) /(K)$.

It can be seen that these equations are in the same form as the standard Lusk equations (42). Lipid oxidized $=(-1) \times$ lipid synthesized. Calculation of oxidation rates merely requires the use of appropriate constants in Eqs. 13 and 14. 
Derivation of Lusk equations for carbohydrate if $R Q>1.00$. Further considering Eqs. 9 and 9a, total moles glucose carbons converted to $\mathrm{CO}_{2}=$ total $\mathrm{CO}_{2}$;

$=\dot{\mathrm{V}} \mathrm{O}_{2} \times \mathrm{RQ}$.

Total moles glucose carbons reacting

$=$ lipid carbons $+\mathrm{CO}_{2}$ carbons.

Using Eqs. 8 and 12 in 9 and $9 \mathrm{a}$, total moles lipid carbons synthesized $=\left[\right.$ Excess $\left.\mathrm{CO}_{2}\right] \times[(R Q L) /(1-R Q L)]$;

$=\left[\dot{\mathrm{V}}_{2} \times(\mathrm{RQ}-1)\right] \times[(R Q L) /(1-R Q L)]$.

Using Eqs. $15-17$, total moles of glucose reacting: $=\left\{\left[\mathrm{VOO}_{2} \times(\mathrm{RQ}\right.\right.$ $\left.-1)]+\left[\dot{\mathrm{VO}}_{2} \times \mathrm{RQ} \times(1-R Q L)\right]\right\} /(1-R Q L)=\left[\dot{\mathrm{VO}}_{2}(\mathrm{RQ}-\right.$ $R Q L)] /(1-R Q L)$. Note that this last equation is in the same form as the Lusk equation for glucose oxidation; conversion from this equation to rate of carbohydrate oxidation merely requires the use of the appropriate constants, i.e., the Lusk equation for glucose oxidation when the RQ $>1.00$ includes glucose converted to both lipid and $\mathrm{CO}_{2}$. The calculation of glucose oxidation to $\mathrm{CO}_{2}$, therefore, requires that the glucose converted to lipid be subtracted from the apparent glucose oxidation values.

\section{Acknowledgments}

The authors wish to thank Drs. Gerald M. Reaven, Richard J. Havel, and Samuel Cushman for their contributions to the initial planning of this study; Mr. James Smart and Dr. Nordisk Bethesda for the kind donation of the purified pork insulin; Ms. Marjorie Robinson and the nursing and dietary staff of the Phoenix Clinical Research Section; Beverly Derby, Verna Kuwanhoyioma, and Marilyn Francisco for secretarial assistance; and Tom Anderson, John Brown, Inge Harper, Harlan Osife, Vera Rodriguez, Karen Stone, and Pam Thuillez for technical assistance.

\section{References}

1. Randle, P. J., P. B. Garland, C. N. Hales, and E. A. Newsholme. 1963. The glucose fatty-acid cycle: its role in insulin sensitivity and the metabolic disturbances of diabetes mellitus. Lancet. I:785-789.

2. Randle, P. J., P. H. Sugden, A. L. Kerbey, P. M. Radcliffe, and N. J. Hutson. 1978. Regulation of pyruvate oxidation and the conservation of glucose. Biochem. Soc. Symp. 43:47-67.

3. Newsholme, E. A. 1976. Carbohydrate metabolism in vivo: regulation of the blood glucose level. Clin. Endocrinol. Metab. 5:543578.

4. Robinson, A. M., and D. H. Williamson. 1980. Physiological roles of ketone bodies as substrates and signals in mammalian tissues. Physiol. Rev. 60:143-187.

5. Randle, P. J., P. B. Garland, C. N. Hales, E. A. Newsholme, R. M. Denton, and C. I. Pogson. 1966. Interactions of metabolism and the physiological role of insulin. Recent Prog. Horm. Res. 22:148.

6. Garland, P. B., E. A. Newsholme, and P. J. Randle. 1964. Regulation of glucose uptake by muscle. Biochem. J. 93:665-678.

7. Ferrannini, E., E. J. Barrett, S. Bevilacqua, and R. A. DeFronzo. 1983. Effect of fatty acids on glucose production and utilization in man. J. Clin. Invest. 72:1737-1747.

8. Ruderman, N. B., C. J. Toews, and E. Shafrir. 1969. Role of free fatty acids in glucose homeostasis. Arch. Intern. Med. 123:299313.

9. Ashour, B., and R. G. Hansford. 1983. Effect of fatty acids and ketones on the activity of pyruvate dehydrogenase in skeletal-muscle mitochondria. Biochem. J. 214:725-736.
10. Maizels, E. Z., N. B. Ruderman, M. N. Goodman, and D. Lau. 1977. Effect of acetoacetate on glucose metabolism in the soleus and extensor digitorum longus muscles of the rat. Biochem. J. 162: 557-568.

11. Rennie, M. J., and J. O. Holloszy. 1977. Inhibition of glucose uptake and glycogenolysis by availability of oleate in well-oxygenated perfused skeletal muscle. Biochem. J. 168:161-170.

12. Balasse, E. O., and M. A. Neef. 1973. Influence of nicotinic acid on the rates of turnover and oxidation of plasma glucose in man. Metab. Clin. Exp. 22:1193-1204.

13. Paul, P., B. Issekutz, and H. I. Miller. 1966. Interrelationship of free fatty acids and glucose metabolism in the dog. Am. J. Physiol. 211:1313-1320.

14. Gomez, F., E. Jequier, V. Chabot, V. Buber, and J. P. Felber. 1972. Carbohydrate and lipid oxidation in normal human subjects: its influence on glucose tolerance and insulin response to glucose. Metab. Clin. Exp. 21:381-391.

15. Balasse, E. O., and M. A. Neef. 1974. Operation of the "glucosefatty acid cycle" during experimental elevations of plasma free fatty acid levels in man. Eur. J. Clin. Invest. 4:247-252.

16. Balasse, E. O. 1971. Effect of free fatty acids and ketone bodies on glucose uptake and oxidation in the dog. Horm. Metab. Res. 3: 403-409.

17. Thiebaud, D., R. A. DeFronzo, E. Jacot, A. Golay, K. Acheson, E. Maeder, E. Jequier, and J.-P. Felber. 1982. Effect of long chain triglyceride infusion on glucose metabolism in man. Metab. Clin. Exp. 31:1128-1136.

18. Rousselle, J., A. Buckert, P. Pahud, E. Jequier, and J.-P. Felber. 1982. Relationship between glucose oxidation and glucose tolerance in man. Metab. Clin. Exp. 31:866-870.

19. Nestel, P. J., K. F. Carroll, and M. S. Silverstein. 1964. Influence of free-fatty-acid metabolism on glucose tolerance. Lancet. II: 115-117.

20. Schalch, D. S., and D. M. Kipnis. 1965. Abnormalities in carbohydrate tolerance associated with elevated plasma nonesterified fatty acids. J. Clin. Invest. 44:2010-2020.

21. Felber, J.-P., and A. Vannotti. 1964. Effects of fat infusion on glucose tolerance and insulin plasma levels. Med. Exp. 10:153-156.

22. Pelkonen, R., T. A. Miettinen, M.-R. Taskinen, and E. A. Nikkila. 1968. Effect of acute elevation of plasma glycerol, triglyceride and FFA levels on glucose utilization and plasma insulin. Diabetes. 17:76-82.

23. National Diabetes Data Group. 1979. Classification and diagnosis of diabetes mellitus and other categories of glucose intolerance. Diabetes. 28:1039-1057.

24. Goldman, R. F., and E. R. Buskirk. 1961. A method for underwater weighing and the determination of body density. In Techniques for Measuring Body Composition. J. Brozek and A. Herschel, editors. National Academy of Sciences-National Research Council, Wash. DC. 78-106.

25. Keys, A., and J. Brozek. 1953. Body fat in adult man. Physiol. Rev. 33:245-325.

26. Havel, R. J., A. Naimark, and C. F. Borchgrevink. 1963. Turnover rate and oxidation of free fatty acids of blood plasma in man during exercise: studies during continuous infusion of palmitate1-C14. J. Clin. Invest. 42:1054-1063.

27. Hagenfeldt, L., A. Wennlund, P. Felig, and J. Wahren. 1981. Turnover and splanchnic metabolism of free fatty acids in hyperthyroid patients. J. Clin. Invest. 67:1672-1677.

28. DeFronzo, R. A., J. D. Tobin, and R. Andres. 1979. Glucose clamp technique: a method for quantifying insulin secretion and resistance. Am. J. Physiol. 237:E214-E223.

29. Jequier, E. 1981. Long-term measurement of energy expenditure in man: direct or indirect calorimetry? In Recent Advances in Obesity Research. III. P. Björntorp, M. Cairella, and A. N. Howard, editors. Libbey, London. 130-135.

30. Lusk, G. 1924. Animal calorimetry: analysis of the oxidation of mixtures of carbohydrate and fat. J. Biol. Chem. 59:41-42. 
31. Herbert, V., K. Lau, C. W. Gottlieb, and S. J. Bleicher. 1965. Coated charcoal immunoassay of insulin. J. Clin. Endocrinol. Metab. 25:1375-1384.

32. Yalow, R. S., and S. A. Berson. 1960. Immunoassay of endogenous plasma insulin in man. J. Clin. Invest. 39:1157-1167.

33. Best, J. D., J. G. Judzewitsch, M. A. Pfeifer, J. C. Beard, J. B. Halter, and D. Porte, Jr. 1982. The effect of chronic sulfonylurea therapy on hepatic glucose production in non-insulin dependent diabetes. Diabetes. 31:333-338.

34. Soloni, F. G., and L. C. Sardina. 1973. Colorimetric microdetermination of free fatty acids. Clin. Chem. 19:419-424.

35. Howard, B. V., P. J. Savage, M. Nagulesparan, L. J. Bennion, R. H. Unger, and P. H. Bennett. 1979. Evidence for marked sensitivity to the antilipolytic action of insulin in obese maturity-onset diabetics. Metab. Clin. Exp. 28:744-750.

36. Dole, V. P. 1956. A relation between non-esterified fatty acids in plasma and the metabolism of glucose. J. Clin. Invest. 35:150-154.

37. Trout, D. L., E. H. Estes, Jr., and S. J. Friedberg. 1960. Titration of free fatty acids of plasma: a study of current methods and a new modification. J. Lipid Res. 1:199-202.

38. Peters, J. P., and D. D. VanSlyke. 1946. Quantitative clinical chemistry. Interpretations. Second ed. Bailliere, Tindall, and Cox, London. 5-12.

39. Frayn, K. N. 1983. Calculation of substrate oxidation rates in vivo from gaseous exchange. J. Appl. Physiol. Respir. Environ. Exercise Physiol. 55:628-634.

40. Steele, R. 1959. Influences of glucose loading and of injected insulin on hepatic glucose output. Ann. NY Acad. Sci. 82:420-430.

41. Issekutz, B., P. Paul, H. I. Miller, and W. M. Bortz. 1968. Oxidation of plasma FFA in lean and obese humans. Metab. Clin. Exp. 17:62-73.

42. Hagenfeldt, L., J. Wahren, B. Pernow, and L. Raf. 1972. Uptake of individual free fatty acids by skeletal muscle and liver in man. J. Clin. Invest. 51:2324-2330.

43. Hagenfeldt, L. 1979. Metabolism of free fatty acids and ketone bodies during exercise in normal and diabetic man. Diabetes. 28(Suppl. 1):66-70.

44. Miles, J. M., M. W. Haymond, S. L. Nissen, and J. E. Gerich. 1983. Effects of free fatty acid availability, glucagon excess, and insulin deficiency on ketone body production in post absorptive man. J. Clin. Invest. 71:1554-1561.

45. Dietze, G., M. Wicklmayr, and H. Mehnert. 1978. On the key role of ketogenesis for the regulation of glucose homeostasis during fasting: intrahepatic control, ketone levels and peripheral pyruvate oxidation. In Biochemical and Clinical Aspects of Ketone Body Metabolism. H. D. Soling and C. D. Seufert, editors. Thieme, Stuttgart. 213-225.

46. Owen, O. E., V. E. Trapp, G. A. Reichard, Jr., M. A. Mozzoli, J. Moctezuma, P. Paul, C. L. Skutches, and G. Boden. 1983. Nature and quantity of fuels consumed in patients with alcoholic cirrhosis. $J$. Clin. Invest. 72:1821-1832.

47. Hammond, V. A., and D. G. Johnston. 1983. Effects of noradrenaline and insulin on lipolysis and fatty acid re-esterification in isolated human adipocytes. Diabetologia. 25:161.

48. Thiebaud, D., E. Jacot, R. A. DeFronzo, E. Maeder, E. Jequier, and J.-P. Felber. 1982. The effect of graded doses of insulin on total glucose uptake, glucose oxidation, and glucose storage in man. Diabetes. 31:957-963.

49. Foss, M. C., F. V. Vlachokosta, L. N. Cunningham, and T. T. Aoki. 1982. Restoration of glucose hemostasis in insulin-dependent diabetic subjects. Diabetes. 31:46-52.

50. Zierler, K. L., and D. Rabinowitz. 1964. Effect of very small concentrations of insulin on forearm metabolism. Persistence of its action on potassium and free fatty acids without its effect on glucose. J. Clin. Invest. 43:950-952.

51. Howard, B. V., I. Klimes, B. Vasquez, D. Brady, M. Nagulesparan, and R. H. Unger. 1984. The antilipolytic action of insulin in obese subjects with resistance to its glucoregulatory action. J. Clin. Endocrinol. Metab. 58:544-548.

52. Newman, W. P., and R. G. Brodows. 1983. Insulin action during acute starvation: evidence for selective insulin resistance in normal man. Metab. Clin. Exp: 32:590-596.

53. Stralfors, P., and P. Belfrage. 1984. Reversible phosphorylation of hormone-sensitive lipase/cholesterol ester hydrolase in the hormonal control of adipose tissue lipolysis and of adrenal steroidogenesis. In Enzyme Regulation by Reversible Phosphorylation: Further Advances. P. Cohen, editor. Elsevier Biomedical Press, Amsterdam. 2:27-62.

54. Shulman, G. I., P. E. Williams, J. E. Liljenquist, W. W. Lacy, U. Keller, and A. D. Cherington. 1980. Effect of hyperglycemia independent of changes in insulin or glycogen on lipolysis in the conscious dog. Metab. Clin. Exp. 29:317-320.

55. Nestel, P. J. 1967. Relationship between FFA flux and TGFA influx in plasma before and during the infusion of insulin. Metab. Clin. Exp. 16:1123-1132.

56. Hers, H.-G., and E. Van Schaftingen. 1982. Fructose 2,6biphosphate 2 years after its discovery. Biochem. J. 206:1-12.

57. Jacot, E., R. A. DeFronzo, E. Jequier, E. Maeder, and J.-P. Felber. 1982. The effect of hyperglycaemia, hyperinsulinaemia, and route of glucose administration on glucose oxidation and glucose storage. Metab. Clin. Exp. 31:922-930.

58. Wolfe, R. R., J. R. Allsop, and J. F. Burke. 1979. Glucose metabolism in man: responses to intravenous glucose infusion. Metab. Clin. Exp. 28:210-220.

59. Mosora, F., M. Lacroix, A. Luyckx, N. Pallikarakis, F. Pirnay, G. Krentowski, and P. Lefebvre. 1981. Glucose oxidation in relation to the size of the oral glucose loading dose. Metab. Clin. Exp. 30: 1143-1149.

60. DeFronzo, R. A., E. Jacot, E. Jequier, E. Maeder, J. Wahren, and J.-P. Felber. 1981. The effect of insulin on the disposal of intravenous glucose. Diabetes. 30:1000-1007.

61. Bogardus, C., P. Thuillez, E. Ravussin, B. Vasquez, M. Narimiga, and S. Azhar. 1983. Effect of muscle glycogen depletion on in vivo insulin action in man. J. Clin. Invest. 72:1605-1610.

62. Depocas, F. 1964. Regulation of glucose oxidation in the white rat. Am. J. Physiol. 206:113-118.

63. Verdonk, C. A., R. A. Rizza, and J. E. Gerich. 1981. Effects of plasma glucose concentration on glucose utilization and glucose clearance in normal man. Diabetes. 30:535-537.

64. Felber, J.-P., H. U. Meyer, B. Curchod, H. U. Iselin, J. Rousselle, E. Maeder, P. Pahud, and E. Jequier. 1981. Glucose storage and oxidation in different degrees of human obesity measured by continuous indirect calorimetry. Diabetalogia. 20:39-44.

65. Boden, G., T. K. Ray, R. H. Smith, and O. E. Owen. 1983. Carbohydrate oxidation and storage in obese non-insulin-dependent diabetic patients. Diabetes. 32:982-987.

66. Katz, L. D., M. G. Glickman, S. Rapoport, E. Ferrannini, and R. A. DeFronzo. 1983. Splanchnic and peripheral disposal of oral glucose in man. Diabetes. 32:675-679.

67. Meistas, M. T., and T. T. Aoki. 1983. Hepatic $\mathrm{CO}_{2}$ production following oral glucose administration in man. Clin. Res. 31:504A (Abstr.)

68. Opie, L. H., and P. G. Walfish. 1963. Plasma free fatty acid concentrations in obesity. New Engl. J. Med. 268:757-760.

69. Bjorntorp, P., H. Bergman, E. Varnauskas, and B. Lindholm. 1969. Lipid mobilization in relation to body composition in man. Metab. Clin. Exp. 18:840-851. 